\title{
North East
}

\section{Map 6.1 Population density: by local or unitary authority, 2008}

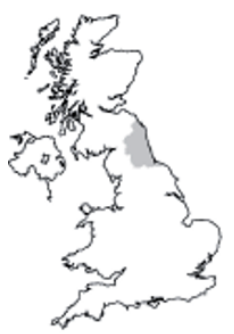

Population density, 2008 (people per sq km)

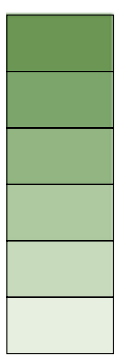

2,500 or over
$1,000-2,499$
$500-999$
$250-499$
$100-249$
99 or under

1 Wansbeck

2 Blyth Valley

3 North Tyneside

4 South Tyneside

5 Sunderland

6 Newcastle upon Tyne

7 Easington

8 Chester-le-Street

9 Hartlepool UA

10 Stockton-on-Tees UA

11 Middlesbrough UA

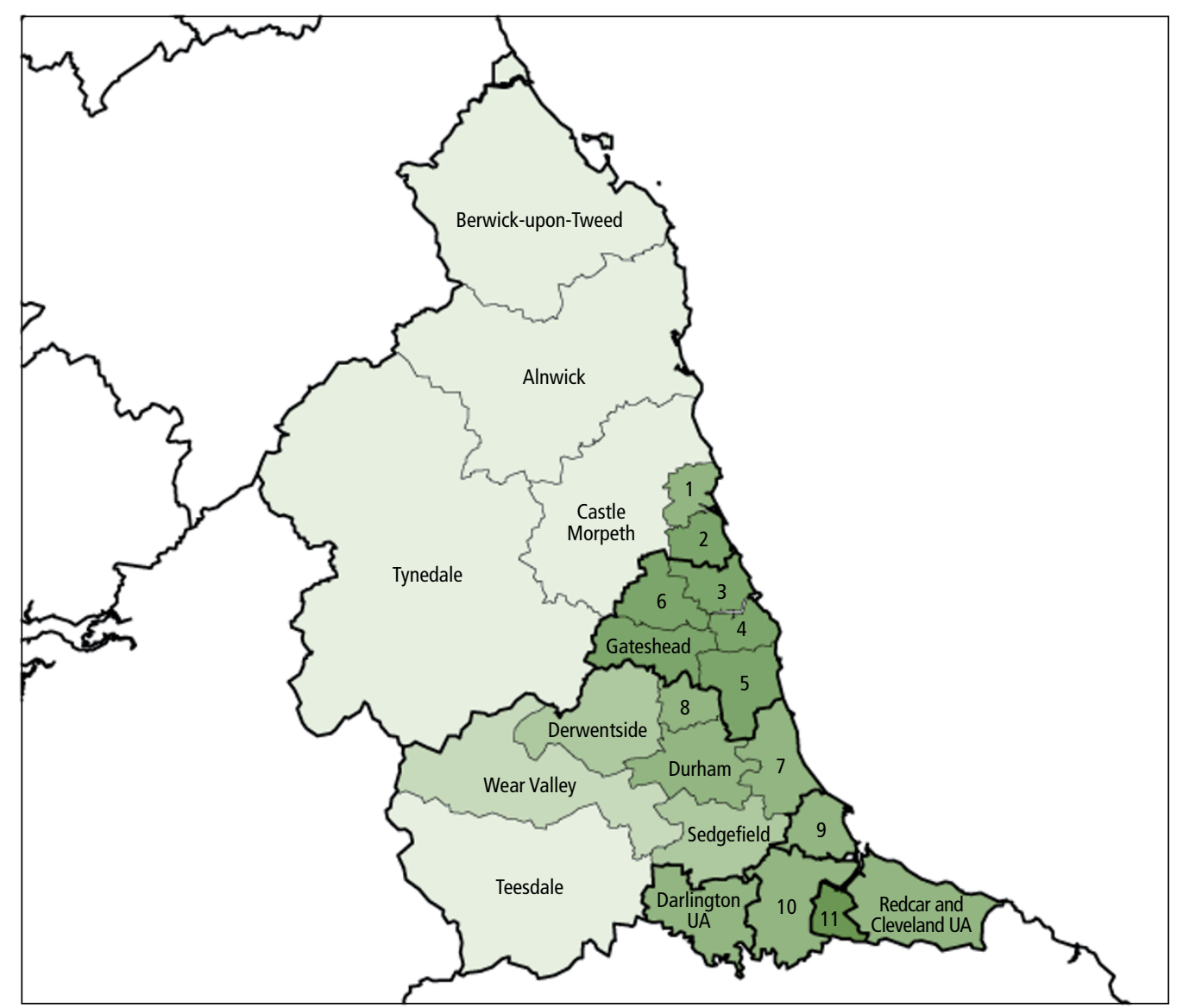

- The North East had a population of 2.6 million in mid-2008, an increase of 1.3 per cent since 2003 . This compares with an overall increase of 3.1 per cent for the UK over the same period (Online table 1.2).

- People over state pension age (65 and over for men and 60 and over for women) in the North East in 2008 made up 20.1 per cent of the population, compared with 17.9 per cent for the under-16s. This compares with averages for the UK of 19.2 per cent and 18.8 per cent respectively (Online table 10.3).

- In the North East, men aged 65 in 2006-08 could expect to live another 16.7 years and women 19.3 years. This compares with 17.5 and 20.2 years in the UK as a whole (Online table 6.8).

- In the North East, 44.9 per cent of pupils achieved five or more grades $A^{*}-C$ at GCSE level or equivalent including English and mathematics in 2007/08, compared with 47.7 per cent for the UK as a whole (Online table 4.8).
- The unemployment rate in the North East stood at 9.3 per cent in the fourth quarter of 2009, higher than the UK rate of 7.8 per cent (Online table 1.1).

- The proportion of children living in workless households in the second quarter of 2009 was higher in the North East (21 per cent) than the England average (17 per cent) (Online table 8.6).

- In April 2009, the median gross weekly earnings for full-time employees on adult rates who were resident in the North East was $£ 439$, lower than the UK median of $£ 489$ (Online table 9.19).

- Labour productivity (gross value added per hour worked) in the North East in 2008 was 9.9 per cent below the UK average (Online table 3.2).

- North East local authorities recycled 28 per cent of household waste in 2007/08 compared with an England average of 35 per cent (Online table 5.11). 